\title{
Persepsi Anggota Dewan Perwakilan Rakyat Daerah (DPRD) Kota Depok Terhadap Pembangunan Kesehatan di Depok
}

\section{Perception of Depok City Regional Representatives Council (DPRD) on Health Development in Depok 2018}

\author{
Susilawati $^{(1)}$, Andri Yan ${ }^{(1)}$ \\ ${ }^{(1)}$ Prodi Kesehatan Masyarakat, Sekolah Tinggi Ilmu Kesehatan Raflesia, Depok, Indonesia \\ Korespondensi Penulis: Susilawati, Program Studi Kesehatan Masyarakat, \\ Sekolah Tinggi Ilmu Kesehatan Raflesia \\ Email: susi28057@gmail.com
}

\begin{abstract}
ABSTRAK
Penelitian ini bertujuan untuk menggali persepsi permasalahan utama kesehatan di Depok menurut anggota Dewan Perwakilan Rakyat Daerah (DPRD) Depok dan Kepala Dinas Kesehatan Kota Depok. Penelitian ini menggunakan metode kualitatif dengan desain penelitian deskriptif. Subyek penelitian adalah tujuh belas anggota DPRD Depok. Tehnik pengumpulan data yang digunakan adalah observasi, wawancara, dan dokumentasi. Tehnik analisa yang digunakan adalah reduksi data, penyajian data dan verifikasi data. Uji validasi data yang digunakan yaitu triangulasi tehnik dan sumber. Berdasarkan pernyataan informan, beberapa permasalahan kesehatan utama yang masih terjadi di Kota Depok diantaranya adalah belum cukupnya sarana dan prasarana pelayanan kesehatan, rendahnya perilaku kesehatan masyarakat, terbatasnya akses pelayanan kesehatan miskin, masih kurangnya tenaga kesehatan, adanya penyakit menular dan tidak menular, masih terbatasnya kerjasama Dinas Kesehatan dan Swasta dalam pelayanan Jaminan Kesehatan Nasional, permasalahan kesehatan lingkungan, penyalahgunaan narkotika dan obat-obatan terlarang dan kurangnya pengelolaan sistem informasi manajemen khususnya pada Rumah Sakit Umum Daerah.
\end{abstract}

Kata Kunci : Persepsi, Dewan Perwakilan Rakyat Daerah, Pembangunan Kesehatan, Permasalahan Kesehatan.

\section{ABSTRACT}

This study aims to explore perceptions of the main health problems in Depok according to members of the Depok Regional House of Representatives (DPRD) and the Head of Depok City Health Office. This research uses qualitative methods with descriptive research design. The research subjects were seventeen Depok DPRD members. Data collection techniques used in this research are observation, interviews, and documentation. Data reduction, data presentation and data verification were used in data analysis process. Triangulation of techniques and sources have been performed. The Informants stated several main problems in Depok City which are inadequate number of health service facilities and the infrastructures, unhealthy behavior, inequitable access to health Care by the poor in community, lack of health workers, the existence of infectious and non-communicable diseases, limited collaboration between the government and private sector specifically in national health insurance scheme, environmental health issues, drug abuse and lack of performance of information management systems especially at the Regional General Hospital.

Keywords: Perception, Regional House of Representatives, Health Development, Health Problem 


\section{PENDAHULUAN}

Pembangunan

adalah upaya

multidimensi untuk mencapai kualitas hidup seluruh penduduk yang lebih baik. Pembangunan kesehatan adalah proses yang berlangsung terus menerus dan progresif untuk meningkatkan derajat kesehatan masyarakat. Pembangunan kesehatan di Indonesia dilaksanakan oleh semua komponen bangsa yang bertujuan untuk meningkatkan kesadaran, kemauan dan kemampuan hidup sehat manusia Indonesia agar terwujud derajat kesehatan masyarakat yang setinggi-tingginya, sebagai investasi bagi pembangunan sumber daya manusia yang produktif secara sosial dan ekonomis.

Undang-Undang No. 17 tahun 2007 tentang Rencana Pembangunan Jangka Panjang Nasional (RPJPN) tahun 2005-2025 telah ditetapkan bahwa visi pembangunan nasional tahun 2005-2025 adalah Indonesia yang mandiri, maju, adil dan makmur. Dalam mewujudkan visi pembangunan nasional tersebut ditempuh melalui delapan misi pembangunan nasional. Salah satu misinya adalah mewujudkan bangsa yang berdaya saing, yaitu mengedepankan antara lain pembangunan sumber daya manusia yang berkualitas dan berdaya saing. Pembangunan sumber daya manusia yang berkualitas ini berkaitan dengan pembangunan kesehatan. Pembangunan kesehatan dilakukan dengan memperhatikan dinamika kependudukan, epidemiologi penyakit, perubahan ekologi dan lingkungan, kemajuan iptek, globalisasi dan demokratisasi dengan semangat kemitraan dan kerjasama lintas sektoral. Pembangunan Kesehatan diarahkan kepada peningkatan perilaku dan kemandirian serta upaya promotif dan preventif.

Pembangunan di Indonesia, termasuk pembangunan kesehatan, tidak terlepas dari peran berbagai Penyelenggara Pemerintahan yang ada. Di Indonesia sendiri tidak hanya Lembaga eksekutif yang berperan, namun juga terdapat Lembaga legislatif dan yudikatif. Dan dalam pembangunan khususnya kesehatan, tidak hanya Lembaga eksekutif yang berperan, juga terdapat peran dari Lembaga legislatif. Lembaga legislatif diberi hak yang cukup luas yang secara khusus diarahkan untuk menyerap serta menyalurkan aspirasi masyarakat dalam pembuatan suatu kebijakan baik di tingkat nasional maupun daerah.
Saat ini Indonesia telah melaksanakan otonomi daerah, dimana dalam pelaksanaannya daerah yang telah otonom berhak mengatur dan mengurus sendiri urusan pemerintahan dan kepentingan masyarakat setempat. Serupa dengan tingkat Nasional, di daerah juga terdapat lembaga legislatif yang diwujudkan dengan melalui Dewan Perwakilan Rakyat Daerah (DPRD) yang mana sesuai dengan Undang-Undang Nomor 23 Tahun 2014 disebutkan bahwa DPRD memiliki fungsi dalam pembentukan Peraturan daerah, anggaran dan pengawasan terhadap kepala daerah.

Fungsi-fungsi DPRD ini masih diketemukan kelemahan pelaksanaannya, salah satunya adalah masih ditemukannya kelemahan Anggota DPRD dalam pengelolaan keuangan daerah yaitu masih rendahnya peran anggota DPRD dalam keseluruhan proses anggaran (APBD), baik dalam hal perencanaan, pelaksanaan, pelaporan maupun pengawasan program kerja eksekutif (Winarna dan Murni, 2007). Hal ini berakibat program kerja yang ada dalam anggaran daerah belum sesuai dengan prioritas dan preferensi daerah. Masih adanya masyarakat yang menilai anggota DPRD belum berperan dalam menjalankan tugasnya dengan baik sebagai anggota DPRD dalam meningkatkan kesejahteraam masyarakat (Sembiring, 2014). Kinerja anggota DPRD belum optimal sehingga belum mampu menyuarakan aspirasi rakyat, tidak jelas visi, misi tujuan, sasaran rencana program, hanya memikirkan kepentingan sendiri dan kelompok partainya (Puspita, 2008).

Penggalian peran DPRD di daerah dalam pembangunan kesehatan dirasa perlu untuk dapat melihat sejauh mana peran Lembaga tersebut dalam pembangunan kesehatan di daerah. Oleh karena itu, penelitian ini bertujuan untuk mengeksplorasi persepsi anggota DPRD Kota Depok terkait dengan pembangunan kesehatan, anggaran kesehatan daerah ideal, permasalahan kesehatan dan solusi permasalahan kesehatan di Kota Depok, Jawa Barat.

\section{SUBYEK DAN METODE}

Penelitian ini menggunakan pendekatan kualitatif dengan metode studi kasus. Subyek penelitian adalah anggota DPRD Depok sebanyak 17 orang dan seorang Kepala Dinas Kesehatan Depok. Tehnik pengumpulan data adalah observasi, wawancara mendalam dan 
dokumentasi. Observasi dilakukan mengamati rapat paripurna yang dilaksanakan di DPRD Depok. Tehnik analisis dalam penelitian ini adalah tehnik analisis model interaktif yang dikembangkan oleh Miles dan Huberman (Sugiyono, 2015: 91) yaitu reduksi data, penyajian data dan verifikasi data. Langkah yang dilakukan sebelum menganalisis data adalah transkrip data memindahkan data dalam bentuk rekaman ke dalam bentuk tulisan secara lengkap tanpa mengubah informasi yang ada di dalam alat perekam tersebut. Rekaman yang sudah ditranskrip langsung dipindahkan ke komputer untuk siap dianalisis (excel). Selanjutnya pengkodean yaitu mengidentifikasi kata-kata atau isi atau paragraf yang digunakan. Metode analisis yang digunakan adalah constant comparison analysis (Glasser dan Strauss) ada tiga tahapan dalam metode ini yaitu 1) open coding yaitu membagi data menjadi bagian-bagian kecil, 2) Axial Coding yaitu mengelompokan data dalam beberapa kategori, 3) Selective coding yaitu peneliti mengembangkan satu atau lebih tema yang menggambarkan setiap bahasan tema (Strauss \& Corbin, 1998 dalam Onwougbuzie, 2009, diambil dari Martha Evi, 2017). Tahapan selanjutnya analisis isi yaitu elevansi teori yang sudah ada sebelumnya terhadap hasil penelitian yang sudah dikumpulkan.

\section{HASIL}

Informan penelitian ini ialah 17 anggota DPRD Depok yang terdiri atas 9 perempuan dan 8 laki-laki, dengan distribusi rata-rata umur 49 tahun, umur tertinggi 67 tahun, umur terendah 27 tahun. Distribusi komisi anggota DPDRD Depok yang berhasil diwawancarai dari komisi D 6 orang, komisi B 5 orang, komisi C 3 orang, dan komisi A 3 orang. Distribusi fraksi anggota DPRD yang diteliti 5 orang dari fraksi Gerindra, 3 orang dari fraksi PDIP, 3 orang dari fraksi PKS, 3 orang dari fraksi PAN, dan dari fraksi PPP, Demokrat dan Hanura masing-masing satu orang. Lama menjabat anggota DPRD Depok yang berhasil diwawancarai rata-rata 5,2 tahun, minimal menjabat selama 4 tahun dan paling lama 14 tahun. Informasi mengenai karakteristik informan dapat dilihat pada tabel 1 .

Mayoritas informan $(\mathrm{n}=10,59 \%)$ yang berasal dari anggota DPRD Kota Depok menjawab bahwa presentase ideal anggaran kesehatan daerah yang berasal dari seluruh anggaran di daerah yakni 20\%. Selain itu terdapat sebagai informan yang menyatakan bahwa anggaran kesehatan ideal di daerah yakni sebesar $10 \%$ dari total anggaran di daerah. Distribusi jawaban informan terkait dengan besaran presentase anggaran kesehatan di daerah dapat dilihat pada tabel 2 .

Tabel 1. Identitas Informan

\begin{tabular}{|c|c|c|c|}
\hline Variabel & Kategori & $\begin{array}{c}\text { Frekuensi } \\
(\mathbf{n}=17)\end{array}$ & $\begin{array}{c}\text { Persentase } \\
(\%)\end{array}$ \\
\hline \multirow[t]{2}{*}{ Jenis Kelamin } & Laki - Laki & 9 & 52,9 \\
\hline & Perempuan & 8 & 47,1 \\
\hline \multirow[t]{4}{*}{ Komisi } & $\mathrm{A}$ & 3 & 18 \\
\hline & B & 5 & 29 \\
\hline & $\mathrm{C}$ & 3 & 18 \\
\hline & $\mathrm{D}$ & 6 & 35 \\
\hline \multirow[t]{7}{*}{ Fraksi } & Demokrat & 1 & 6 \\
\hline & Gerindra & 5 & 29 \\
\hline & Hanura & 1 & 6 \\
\hline & PAN & 3 & 18 \\
\hline & PDIP & 3 & 18 \\
\hline & PKS & 3 & 18 \\
\hline & PPP & 1 & 6 \\
\hline \multirow[t]{3}{*}{ Lama menjabat } & 1 Periode & 14 & 82 \\
\hline & 2 Periode & 2 & 12 \\
\hline & 3 Periode & 1 & 6 \\
\hline
\end{tabular}


Tabel 2. Presentase Anggaran Kesehatan

\begin{tabular}{lccc}
\hline \multicolumn{1}{c}{ Variabel } & Kategori & $\begin{array}{c}\text { Jumlah } \\
(\mathbf{n})\end{array}$ & $\begin{array}{c}\text { Persentase } \\
(\boldsymbol{\%})\end{array}$ \\
\hline \multirow{2}{*}{ Persentase anggaran kesehatan yang } & $30 \%$ & 3 & 18 \\
ideal & $20 \%$ & 10 & 59 \\
& $10 \%$ & 4 & 24 \\
\hline
\end{tabular}

\section{Pembangunan Kesehatan investasi atau konsumsi?}

Mayoritas informan yang berasal dari Anggota DPRD Depok menyatakan pembangunan kesehatan adalah investasi $(\mathrm{n}=8$ orang, 47\%). Responden yang menyatakan pembangunan kesehatan adalah konsumsi sebanyak 2 orang (12\%). Sedangkan 7 orang anggota DPRD Depok yang menyatakan bisa dilihat sebagai investasi dan konsumsi. Pembangunan kesehatan suatu konsumsi menurut anggota DPRD Depok karena memandang suatu pelayanan kesehatan yang dikonsumsi oleh masyarakat dan pembangunan kesehatan dinyatakan sebagai investasi karena mengeluarkan modal untuk membangun sarana pelayanan kesehatan. Ada pula pendapat dari anggota DPRD Depok yang menyatakan kesehatan bukan konsumsi dan investasi. Tapi pembangunan kesehatan adalah suatu kewajiban negara untuk menyiapakan pelayanan kesehatan.

"sebenarnya bukan investasi, jadi gimana ya, kalo kesehatan itu kan wajib. Karna semua warga negara itu berhak mendapatkan pelayanan kesehatan, dalam hal ini kita tidak mementingkan untung rugi. Jadi ini masuknya kedalam kewajiban, sarana prasarana itu pemerintah wajib melayani masalah kesehatan bagi masyarakat itu udah tercantum dalam undang - undang, jadi bukannya kita bangun investasi nih rumah sakit ada keuntungannya segala macem jadi bukan konsumsi juga, bukan investasi tapi kewajiban". (Informan A)

\section{Permasalahan Utama dan Solusi Pembangunan Kesehatan di Depok}

Mayoritas Informan yang berasal dari anggota DPRD Kota Depok mengungkapkan bahwa permasalahan utama yakni belum cukupnya sarana dan prasarana pelayanan kesehatan. Selain itu, ditemukan juga persepsi permasalahan kesehatan lainnya ialah rendahnya perilaku kesehatan di kalangan masyarakat, masih kurangnya jumlah tenaga kesehatan dan masih adanya berbagai penyakit menular dan tidak menular. Selain itu, terdapat juga pernyataan yang dikemukakan oleh informan dari Dinas Kesehatan Kota Depok dimana disebutkan bahwa permasalahan kesehatan utama di Kota Depok antara lain pelayanan kesehatan belum terakreditasi baik puskemas maupun klinik swasta pelayanan pertama kesehatan, angka kematian ibu dan bayi masih cukup tinggi. Ada 14 kasus kematian ibu dari data kasus sebelum 16 Oktober 2018, dan ada 16 kasus kematian ibu tahun 2017 serta masih ada 72 kasus kematian bayi, masih adanya kasus gizi buruk dimana masih terdapat 83 kasus gizi buruk dengan penyakit penyerta serta masih adanya berbagai penyakit menular dan tidak menular seperti tuberkulosis, HIV/AIDS, diabetes, hipertensi dan gangguan jiwa berat.

Tabel 3. Permasalahan Utama Pembangunan Kesehatan di Depok

\begin{tabular}{lcc}
\hline $\begin{array}{l}\text { Permasalahan Utama Pembangunan Kesehatan di Depok } \\
\text { menurut anggota DPRD Depok }\end{array}$ & $\begin{array}{c}\text { Jumlah } \\
(\mathbf{n = 1 7})\end{array}$ & Persentase \\
\hline Belum cukupnya sarana dan prasarana pelayanan kesehatan & 5 & 29 \\
Rendahnya perilaku kesehatan & 3 & 18 \\
Kurangnya tenaga kesehatan & 2 & 12 \\
Penyakit Menular dan Tidak menular masih terjadi & 2 & 12 \\
Akses pelayanan kesehatan orang miskin masih terbatas & 1 & 6 \\
Kerjasama Dinkes dan Swasta dalam pelayanan belum optimal & 1 & 6 \\
Permasalahan Kesehatan Lingkungan & 1 & 6 \\
Penyalahan Narkotika dan obat-obatan terlarang & 1 & 6
\end{tabular}




\begin{tabular}{lcc}
$\begin{array}{l}\text { Permasalahan Utama Pembangunan Kesehatan di Depok } \\
\text { menurut anggota DPRD Depok }\end{array}$ & $\begin{array}{c}\text { Jumlah } \\
(\mathbf{n = 1 7})\end{array}$ & Persentase \\
\hline $\begin{array}{l}\text { Sistem Informasi Manajemen Rumah Sakit Umum Daerah } \\
\text { belum optimal }\end{array}$ & 1 & 6 \\
\hline
\end{tabular}

Tabel 4. Cara Penyelesaian Permasalahan Kesehatan di Depok

\begin{tabular}{lcc}
\hline $\begin{array}{l}\text { Solusi yang ditawarkan oleh Anggota DPRD dalam penyelesaian } \\
\text { permasalahan kesehatan di Depok }\end{array}$ & $\begin{array}{c}\text { Jumlah } \\
(\mathbf{n})\end{array}$ & $\begin{array}{c}\text { Persentase } \\
(\boldsymbol{\%})\end{array}$ \\
\hline Pembangunan sarana dan prasarana kesehatan & 3 & $18 \%$ \\
Sosialisasi pola hidup sehat & 10 & $59 \%$ \\
Meningkatkan kerjasama Pemerintah dengan Rumah Sakit Swasta & 1 & $6 \%$ \\
Peningkatan rogram Preventif, Promotif dan Kuratif & 3 & $18 \%$ \\
\hline
\end{tabular}

Informan juga menyebutkan berbagai upaya yang dapat dilakukan dalam pembangunan kesehatan antara lain ialah Pembangunan sarana dan prasarana kesehatan seperti Rumah Sakit, Puskesmas, meningkatkan Sosialisasi pola hidup sehat, meningkatkan kerjasama Pemerintah dengan Rumah Sakit Swasta khususnya dalam pemberian layanan Jaminan Kesehatan Nasional serta peningkatan program Preventif, Promotif dan Kuratif kepada masyarakat.

\section{DISKUSI}

Mayoritas anggota DPRD Kota Depok telah tepat mempersepsikan bahwa pembangunan kesehatan merupakan sebuah investasi. Pembangunan kesehatan seyogyanya perlu dipersepsikan sebagai sebuah investasi untuk mendapatkan sumber daya manusia yang sehat sehingga mampu berproduktifitas secara optimal karena tidak mengalami kesakitan, ketidakmampuan bekerja, kecacatan dan kematian. Sedangkan dalam elemen konsumsi pembangunan kesehatan tidak dapat dilihat sebagai unsur yang dapat memuaskan keinginan (wants) manusia. Setidaknya ada dua sumber daya ekonomi yang akan dihasilkan dari program kesehatan yaitu penambahan tenaga dan pendapatan nasional serta pembentukan modal (capital formation) (Karma Wisana, 2001). Pembangunan kesehatan dapat dilihat sisi investasi pada konsep biaya pengembangan (development cost concept) yaitu konsep yang membandingkan kerugian investasi dari merawat seorang anak yang meninggal sebelum si anak sempat memberikan kontribusi penuh pada perekonomian dengan besarnya investasi terhadap anak tersebut agar ia dapat memberikan kontribusi penuh (Schultz, 1962 dari Karma Wisana, 2001). Oleh karena itu pentingnya persepsi pelaku pembangunan kesehatan sebagai investasi, sehingga pelaku pembangunan tidak segan untuk mengeluarkan dana kesehatan untuk mendapatkan modal sumber daya manusia Indonesia yang produktif.

Persentase anggaran kesehatan yang ideal menurut mayoritas anggota DPRD Kota Depok yakni $20 \%$ dari total seluruh total anggaran daerah. Pada Undang-Undang No 36 pasal 171 tahun 2009 menyatakan alokasi belanja di bidang kesehatan minimal $10 \%$ dari Anggaran Pendapatan dan Belanja Daerah di luar gaji. Ini berarti ada kesadaran untuk mengalokasikan anggaran yang cukup untuk bidang kesehatan sehingga tujuan peningkatan kualiatas masyarakat dapat tercapai secara optimal.

Persamaan persepsi masalah utama kesehatan di Depok antara anggota DPRD Depok dan Dinas Kesehatan pada penyediaan sarana pelayanan kesehatan dan penanggulangan penyakit menular dan tidak menular. Persepsi anggota DPRD Kota Depok dengan Kepala Dinas Kesehatan Depok memiliki kesamaan pada pembangunan fasilitas pelayanan kesehatan. Anggota DPRD melihat dari perlunya penambahan jumlah sarana dan prasarana pelayanan kesehatan sedangkan Kepala Dinas Kesehatan Depok melihat dari peningkatan mutu pelayanan kesehatan melalui akreditasi puskesmas dan klinik. Dinas Kesehatan Kota Depok mencanangkan program pembangunan kesehatan pada penurunan angka kematian ibu 
dan bayi, penurunan jumlah kasus gizi buruk dan penurunan angka penyakit menular dan tidak menular. Sedangkan Anggota DPRD Kota Depok lebih menekankan sosialisasi hidup sehat, peningkatan kerjasama Pemerintah dengan RS swasta serta program preventif, promotif dan kuratif. Benang merah nya adalah untuk menurunkan masalah kasus kematian ibu dan anak, kasus gizi buruk dan prevalensi penyakit menular dan tidak menular dengan sosialisasi hidup sehat, peningkatan kerjasama BPJS dengan RS swasta dan program preventif, promotif dan kuratif.

Program Pembangunan Kesehatan Dinas Kesehatan Kota Depok tahun 2018 memiliki persamaan dengan rencana strategis Kementrian Kesehatan tahun 2015-2019 dalam hal akselerasi pemenuhan akses pelayanan kesehatan ibu, anak, lanjut usia yang berkualitas, mempercepat perbaikan gizi masyarakat, meningkatkan pengendalian penyakit, meningkatkan akses pelayanan kesehatan dasar yang berkualitas. Sedangkan pembangunan kesehatan menurut DPRD Kota Depok memiliki kesamaan dengan rencana strategis Kementrian Kesehatan tahun 20152019 pada akses pelayanan kesehatan dasar yang berkualitas, meningkatkan promosi kesehatan dan pemberdayaan masyarakat, dan pemantapan pelaksanaan sistem jaminan sosial nasional bidang kesehatan.

Terdapat kesamaan persepsi Anggota DPRD Kota Depok dengan pembangunan kesehatan dengan strategi bidang kesehatan dalam Rencana Pembangunan Jangka Menengah Daerah (RPJMD) Kota Depok (Profil Dinas Kesehatan Depok, 2016) yakni pada peningkatan upaya kesehatan terutama promotif dan preventif melalui penguatan pemberdayaan masyarakat, kerjasama dengan stakeholder dan mitra kesehatan, peningkatan kemandirian masyarakat untuk mencapai kualitas lingkungan yang sehat serta perilaku hidup bersih dan sehat, penguatan pelayanan kesehatan pencegahan, pengendalian penyakit menular dan tidak menular, akselarasi pemenuhan akses pelayanan kesehatan ibu dan anak, pemerataan akses pelayanan kesehatan dasar dan rujukan yang berkualitas dan terjangkau serta pemantapan sistem jaminan sosial nasional (SJSN) bidang kesehatan. Kesamaan persepsi pembangunan kesehatan antara legislatif dan ekskutif akan memperkuat kerjasama dalam mewujudkan peningkatan kualitas kesehatan masyarakat.

\section{KESIMPULAN}

Mayoritas informan menyatakan bahwa pembangunan kesehatan merupakan sebuah investasi dan mayoritas informan juga menyatakan bahwa persentase anggaran kesehatan yang ideal menurut anggota DPRD Depok adalah $\geq 10 \%$ dari total seluruh anggaran di daerah. Berbagai permasalahan utama kesehatan telah disebutkan oleh DPRD Kota Depok maupun informan dari Dinas Kesehatan. Terdapat beberapa kesamaan persepsi terkait dengan permasalahan dan upaya kesehatan utama di Kota Depok antara informan dari DPRD Kota Depok dan Dinas Kesehatan Kota Depok. Berdasarkan hal tersebut, perlu dilakukan kerjasama Lembaga Swadaya Masyarakat yang bergerak di bidang Kesehatan dan ahli kesehatan dengan anggota DPRD Depok dan Dinas Kesehatan Depok agar anggota DPRD Depok dan Dinas Kesehatan Depok dapat melihat permasalahan kesehatan secara menyeluruh. Penelitian lanjutan perlu dilakukan untuk dapat melihat secara lebih mendalam terkait dengan persepsi para anggota DPRD Kota Depok dan performanya dalam pelaksanaan fungsinya yang berkaitan dengan agenda kesehatan.

\section{DAFTAR PUSTAKA}

Karma Wisana, I Dewa gede. (2001). Kesehatan sebagai suatu investasi. Jurnal Ekonomi dan Pembangunan Indonesia Vol 1 No 1 Januari 2001.

Dinas Kesehatan Depok. (2013). Rencana Strategis Dinas Kesehatan Provinsi Jawa Barat 20132018, Depok.

Kementrian PPN/Bappenas. (2014). Rencana Pembangunan Jangka Menengah Nasional 2015-2019.

Puspita, Rahmayani Novia. (2008). Hubungan antara persepsi terhadap budaya politik dengan kinerja anggota Dewan Perwakilan Rakyat Daerah (DPRD) Kota Bandung, Surakarta: Universitas Muhammdiyah Surakarta.https://eprints.ums.ac.id/id/eprint/33 5.

Sembiring, Walid Mustafa. (2014). Persepsi Konstituen terhadap anggota DPRD dalam meningkatkan kesejahteraan Masyarakat. Jurnal Ilmu Pemerintahan dan Sosial Politik 2 (2) (2014): 119132.http://ojs.uma.ac.id/index.php/jppuma.

Sugiyono. (2015). Metode Penelitian Kuantitatif dan Kualitiatif. Bandung: Alfabet.

Winarna, Jaka dan Murni Sri. (2007). Pengaruh Personal Background, Political Background, dan Pengetahuan Dewan tentang Anggaran 
Terhadap Peranan DPRD dalam Pengawasan Keuangan Daerah. Surakarta: Universitas Sebelas MaretJOM Fekon, Vol. 4 No. 1 (Februari) 2017 hal 1295-1309. 